\title{
Stabilization of Li-Rich Disordered Rocksalt Oxyfluoride Cathodes by Particle Surface Modification
}

\author{
Andrew J. Naylor,* Ida Källquist, David Peralta, Jean-Frederic Martin, Adrien Boulineau, \\ Jean-François Colin, Christian Baur, Johann Chable, Maximilian Fichtner, Kristina Edström, \\ Maria Hahlin, and Daniel Brandell*
}

Cite This: ACS Appl. Energy Mater. 2020, 3, 5937-5948

Read Online

\section{ACCESS \\ Wl Metrics \& More \\ Article Recommendations \\ Supporting Information}

ABSTRACT: Promising theoretical capacities and high voltages are offered by Li-rich disordered rocksalt oxyfluoride materials as cathodes in lithium-ion batteries. However, as has been discovered for many other Li-rich materials, the oxyfluorides suffer from extensive surface degradation, leading to severe capacity fading. In the case of $\mathrm{Li}_{2} \mathrm{VO}_{2} \mathrm{~F}$, we have previously determined this to be a result of detrimental reactions between an unstable surface layer and the organic electrolyte. Herein, we present the protection of $\mathrm{Li}_{2} \mathrm{VO}_{2} \mathrm{~F}$ particles with $\mathrm{AlF}_{3}$ surface modification, resulting in a much-enhanced capacity retention over 50 cycles. While the specific capacity for the untreated material drops below $100 \mathrm{~mA} \mathrm{~h} \mathrm{~g}^{-1}$ after only 50 cycles, the treated materials retain almost $200 \mathrm{~mA} \mathrm{~h}$

$\mathrm{g}^{-1}$. Photoelectron spectroscopy depth profiling confirms the stabilization of the active material surface by the surface modification and reveals its suppression of electrolyte decomposition.

KEYWORDS: lithium-ion batteries, Li-rich cathodes, disordered rocksalt, particle coatings, surface modifications, surface passivation, photoelectron spectroscopy

\section{INTRODUCTION}

Lithium-ion batteries (LIBs) currently dominate the portable electronics and full electric vehicle markets; however, the cathode is seen as a "bottle-neck" to their further substantial development. While state-of-the-art cathode materials, such as $\mathrm{NMC}\left(\mathrm{LiNi}_{1-x-y} \mathrm{Co}_{x} \mathrm{Mn}_{y} \mathrm{O}_{2}\right)$ and NCA $\left(\mathrm{LiNi}_{1-x-y} \mathrm{Co}_{x} \mathrm{Al}_{y} \mathrm{O}_{2}\right)$, approach capacities of $200 \mathrm{~mA} \mathrm{~h} \mathrm{~g}$, significantly greater capacities can be reached by employing the so-called lithiumrich materials. ${ }^{1,2}$ Many of such materials have been found to exhibit anionic redox reactions, in addition to the transition metal redox chemistry, to compensate for the excess lithium extracted. ${ }^{3}$ However, Li-rich layered materials, such as $\mathrm{Li}\left[\mathrm{Li}_{0.2} \mathrm{Ni}_{0.13} \mathrm{Co}_{0.13} \mathrm{Mn}_{0.54}\right] \mathrm{O}_{2}$, are often subject to oxygen loss, phase transformations, densification, and metal dissolution during cycling, leading to poor practical performance., ${ }^{4,5}$

One promising family of Li-rich cathode materials is the face-centered cubic-structured disordered rocksalt oxyfluorides, based on $\mathrm{Li}_{2} \mathrm{VO}_{2} \mathrm{~F}$. ${ }^{6,7}$ Compared with Li-rich oxides, in the oxyfluorides, oxide anions $\left(\mathrm{O}^{2-}\right)$ are partially substituted for fluoride anions $\left(\mathrm{F}^{-}\right)$, allowing for the $\mathrm{V}^{3+}$ oxidation state. ${ }^{8}$ In theory, the removal of two lithium ions and taking advantage of the $\mathrm{V}^{3+} / \mathrm{V}^{5+}$ multivalent redox couple result in a large specific capacity of $462 \mathrm{~mA} \mathrm{~h} \mathrm{~g}$. Combined with higher operating voltages, due to the higher electronegativity of fluorine over oxygen, these materials can potentially offer impressive energy densities. Other disordered rocksalt structures have also been studied for use as cathode materials. ${ }^{9-13}$
$\mathrm{Li}_{2} \mathrm{VO}_{2} \mathrm{~F}$ exhibits low-volume expansion and no crystalline phase transitions during charge/discharge cycles. In practice, however, upon extraction of $1.8 \mathrm{Li}^{+}$ions per formula unit, the structure becomes destabilized. In addition, a rapid capacity fading is typically observed over the initial cycles, determined by Källquist et al., to be a result of particle degradation beginning at the surface layers and subsequently spreading inwards toward the bulk of the active material particles. ${ }^{14}$ Moreover, disordered rocksalt materials have in general been found to exhibit oxygen-redox activity, ${ }^{13,15}$ which can lead to reactions with the electrolyte and surface layer formation.

The average discharge voltage and cyclability of $\mathrm{Li}_{2} \mathrm{VO}_{2} \mathrm{~F}$ can be improved by substitution of vanadium by other transition metals. ${ }^{16}$ Recently, studies by Baur et al. and Cambaz et al. demonstrated the stabilization of the material through doping $\left(\mathrm{Li}_{2} \mathrm{~V}_{0.5} \mathrm{M}_{0.5} \mathrm{O}_{2} ; \mathrm{M}=\mathrm{Ti}, \mathrm{Mn}, \mathrm{Fe}, \mathrm{Co}\right)$, leading to reduced particle surface reactivity and greater reversibility of the $\mathrm{V}^{3+} / \mathrm{V}^{5+}$ redox couple. ${ }^{17,18}$ Despite the much-improved performance resulting from $\mathrm{Ti}$ - or Fe-doping, the two newly prepared materials have lower theoretical capacities of 350 and

Received: April 15, 2020

Accepted: May 29, 2020

Published: May 29, 2020 
$207 \mathrm{~mA} \mathrm{~h} \mathrm{~g}^{-1}$, respectively (based on some assumptions of the electrochemical activity of $\mathrm{Ti}$ and $\mathrm{Fe}$ ), compared with $\mathrm{Li}_{2} \mathrm{VO}_{2} \mathrm{~F}$. This is also evidenced by the experimentally determined relative initial capacities presented for these materials.

To avoid compromising capacity through material doping, particle coating or surface modification methods can be employed as an alternative strategy. Such treatments are designed to protect the reactive active material from direct contact with the electrolyte. Ideally, the surface is passivated, preventing the rapid capacity decay observed for unmodified materials but allowing close-to-expected theoretical capacities to be achieved. Numerous previous studies investigated performance enhancements through the coating of Li-rich cathode materials with oxides $\left(\mathrm{Al}_{2} \mathrm{O}_{3}, \mathrm{MgO}, \mathrm{TiO}_{2}\right){ }^{19-23}$ $\mathrm{AlF}_{3},{ }^{24-26}$ and $\mathrm{LiFePO}_{4}{ }^{27,28}$ For example, Amalraj et al. showed irreversible capacity losses in the first cycle of 5.1 and $23.2 \%$ for $\mathrm{AlF}_{3}$-coated and uncoated $x \mathrm{Li}_{2} \mathrm{MnO}_{3}$ (1 $x) \mathrm{Li}\left[\mathrm{Mn}_{y} \mathrm{Ni}_{z} \mathrm{Co}_{w}\right] \mathrm{O}_{2}(x=0.4-0.5)$, respectively. Such coatings have typically been employed for more traditional cathode materials such as $\mathrm{LiCoO}_{2}$ (LCO), NMC (including Ni-rich), and NCA materials. ${ }^{29-32}$

Photoelectron spectroscopy (PES) has emerged as the main characterization technique for surface chemistry analysis in batteries due to its high surface sensitivity and ability to determine chemical states. It is the main characterization technique employed in this study. PES probes oxidation states and local bonding environments of atoms within the sample, making it well suited for studies of the reactions at the particle-electrolyte interfaces in electrodes. Furthermore, with synchrotron-based PES, the excitation energy can be tuned to create nondestructive depth profiles. Higher-excitation energies additionally allow the ability to access higher-energy electronic transitions.

Herein, we present the surface stabilization of $\mathrm{Li}_{2} \mathrm{VO}_{2} \mathrm{~F}$ by $\mathrm{AlF}_{3}$ particle surface modifications. Electrodes of $\mathrm{Li}_{2} \mathrm{VO}_{2} \mathrm{~F}$ with surface modifications of up to $3 \mathrm{~mol} \% \mathrm{AlF}_{3}$ were cycled up to 50 cycles and characterized by energy-tuned PES depth profiling. The role of the surface modification was to prevent degradation of the $\mathrm{Li}_{2} \mathrm{VO}_{2} \mathrm{~F}$ material through reactions with the electrolyte.

\section{EXPERIMENTAL METHODS}

2.1. Synthesis, Surface Modification, and Electrode Preparation. 2.1.1. Synthesis. Material handling, the surface modification procedure, electrode, and cell preparation were performed in an argon-filled glovebox $\left(\mathrm{H}_{2} \mathrm{O}, \mathrm{O}_{2}<0.1 \mathrm{ppm}\right)$. The $\mathrm{Li}_{2} \mathrm{VO}_{2} \mathrm{~F}$ material was prepared from $\mathrm{V}_{2} \mathrm{O}_{3}$ (Alfa Aesar, 99.7\%), $\mathrm{Li}_{2} \mathrm{O}$ (Alfa Aesar, 99.7\%), and LiF (Alfa Aesar, 99.9\%) by following the mechanochemical ball-milling procedure, as described elsewhere. ${ }^{6,8,33,34}$

2.1.2. AlF $F_{3}$ Treatment. $\mathrm{Li}_{2} \mathrm{VO}_{2} \mathrm{~F}$ was treated with up to $3 \% \mathrm{AlF}_{3}$ (mol \% between $\mathrm{AlF}_{3}$ and pristine material). The same synthesis procedure was used to produce different $\mathrm{AlF}_{3}$ ratios. For example, to produce $2 \% \mathrm{AlF}_{3}$-treated $\mathrm{Li}_{2} \mathrm{VO}_{2} \mathrm{~F}, 0.0137 \mathrm{~g}$ of $\mathrm{Al}\left(\mathrm{NO}_{3}\right)_{3} \cdot 9 \mathrm{H}_{2} \mathrm{O}$ was dissolved in $20 \mathrm{~mL}$ of methanol. Then, $200 \mathrm{mg}$ of $\mathrm{Li}_{2} \mathrm{VO}_{2} \mathrm{~F}$ was dispersed in this solution, and the resulting mixture was heated to 80 ${ }^{\circ} \mathrm{C}$. Ten milliliters of a solution consisting of $0.0405 \mathrm{~g}$ of $\mathrm{NH}_{4} \mathrm{~F}$ dissolved in $100 \mathrm{~mL}$ of methanol was thereafter added dropwise to the first solution. The temperature was maintained for $2 \mathrm{~h}$, after which the product was recovered by filtration. The resulting powder was treated at $400{ }^{\circ} \mathrm{C}$ for $5 \mathrm{~h}$.

2.1.3. Electrode Preparation. The $\mathrm{Li}_{2} \mathrm{VO}_{2} \mathrm{~F}$-based materials were ball-milled with carbon black (acetylene black, Alfa Aesar) for $3 \mathrm{~h}$ at $300 \mathrm{rpm}$ to form composites. The electrode slurry consisted of $70 \mathrm{wt}$ $\%$ active material, $20 \mathrm{wt} \%$ carbon black, and $10 \mathrm{wt} \%$ poly(vinylidene difluoride) binder (PVDF) (Solvey 6050) mixed with $\mathrm{N}$-methyl-2pyrrolidone (NMP, Alfa Aesar, 99.5\%). The slurry was coated using a doctor blade onto an aluminum foil and dried overnight under vacuum at $80{ }^{\circ} \mathrm{C}$, after which $14 \mathrm{~mm}$ diameter electrodes were punched out and subsequently pressed at 10 tonnes.

2.2. Electrochemical Methods. Electrodes were assembled into CR2032-type coin cells using $\mathrm{Li}$ metal (Rockwood) as counter electrodes. One Viledon disc and one Celgard 2400 disc were used as separators. The electrolyte used was $1 \mathrm{M} \mathrm{LiPF}_{6}$ in a $1: 1 \mathrm{v} / \mathrm{v}$ ethylene carbonate/dimethyl carbonate (EC/DMC) solvent. Galvanostatic cycling was carried out on an Arbin battery cycler at C/20 C-rate, based on the theoretical capacity for $\mathrm{Li}_{2} \mathrm{VO}_{2} \mathrm{~F}$ of $462 \mathrm{~mA} \mathrm{~h} \mathrm{~g}$ between 1.3 and $4.1 \mathrm{~V}$ vs $\mathrm{Li} / \mathrm{Li}^{+}$.

2.3. Characterization Techniques. 2.3.1. X-ray Diffraction $(X R D)$. X-ray diffraction measurements were carried out on a Brüker AXS D8 advance equipped with a $\mathrm{Cu}$ anticathode, either under the protection of a Kapton film or in a purpose-built airtight cell with a beryllium window to avoid any contact with the atmosphere.

2.3.2. Electron Microscopy. Scanning transmission electron microscopy (STEM) images and chemical mappings were recorded with an FEI OSIRIS microscope using an accelerating voltage of 200 $\mathrm{kV}$. STEM images were collected using an annular dark-field detector. Elemental mappings were obtained by energy-dispersive X-ray spectroscopy (EDS).

2.3.3. Photoelectron Spectroscopy. Cells were disassembled inside an argon glovebox; the electrodes were extracted, rinsed with $\sim 1 \mathrm{~mL}$ DMC ( $\geq 99 \%$, Sigma-Aldrich) to wash away excess electrolytes, and allowed to dry in the glovebox atmosphere. Energy-tuned photoelectron spectroscopy (PES) was performed at the Diamond Light Source (Oxfordshire, U.K.) synchrotron using the Surface and Interface Structural Analysis beamline (I09). ${ }^{35}$ Pieces of approximately $10 \mathrm{~mm}^{2}$ in size of the electrode samples were mounted using carbon tape onto copper Omicron-type sample plates and transferred under vacuum in airtight packages to an argon glovebox $\left(\mathrm{O}_{2}, \mathrm{H}_{2} \mathrm{O}<\right.$ $0.1 \mathrm{ppm})$ at the synchrotron. At the synchrotron, an ultrahigh-vacuum (UHV) transfer suitcase was used to transfer samples to the load-lock on the end station of the beamline. For hard X-ray photoelectron spectroscopy (HAXPES) measurements, an excitation energy of 4000 $\mathrm{eV}$ was used. A Si(111) double-crystal monochromator was used to monochromatize photons. For soft X-ray photoelectron spectroscopy (SOXPES), excitation energies corresponding to 200 and $450 \mathrm{eV}$ kinetic energies were used (as given in the Supporting Information, Table S1) to probe constant depths independent of the core level. A plane grating monochromator is used in the soft X-ray branch of the beamline. To minimize the effects of radiation damage on samples and to reduce the influence from inhomogeneities on the samples, a large area was probed with the beam spread out using defocused settings. The probing spot at the sample is estimated to be approximately $300 \mu \mathrm{m}(\mathrm{H}) \times 1 \mathrm{~mm}(\mathrm{~W})$. No charge neutralizer was used during the measurements. Spectra were recorded using a hemispherical VG Scienta EW4000 analyzer set to pass energies of 50 $\mathrm{eV}$ for SOXPES and $100 \mathrm{eV}$ for HAXPES measurements. Probing depths (three times the inelastic mean free path of electrons, IMFP) were calculated using the TPP-M2 equation as detailed in the NIST database, ${ }^{36}$ using parameters for $\mathrm{Li}_{2} \mathrm{VO}_{2} \mathrm{~F}$, as shown in the Supporting Information, Table S2. Approximate depths are estimated as 2, 4, and $17 \mathrm{~nm}$ for the kinetic energies of 200 and $450 \mathrm{eV}$ and an excitation energy of $4000 \mathrm{eV}$, respectively. These depths should be considered as valid for dense inorganic materials such as the active material of the study. However, organic and polymeric materials often have higher IMFP values and hence longer probing depths.

2.4. PES Data Analysis. The software package CasaXPS was used for analysis of photoelectron spectroscopy data, and the Gaussian/ Lorentzian peak shape GL(30) was used throughout the fitting. For spectra measured at constant kinetic energy, energy calibration was performed by setting the binding energy for the $\mathrm{sp}^{3}$-hybridized carbon (C-C) in the deconvoluted $\mathrm{C} 1 \mathrm{~s}$ spectra to $284.8 \mathrm{eV}$. A further adjustment was performed based on the shift of the $\mathrm{Au} 4 \mathrm{f}_{7 / 2}$ between the excitation energies used to measure the $C 1$ s spectra and the spectra of the element being calibrated. Thereby, the total adjustment 

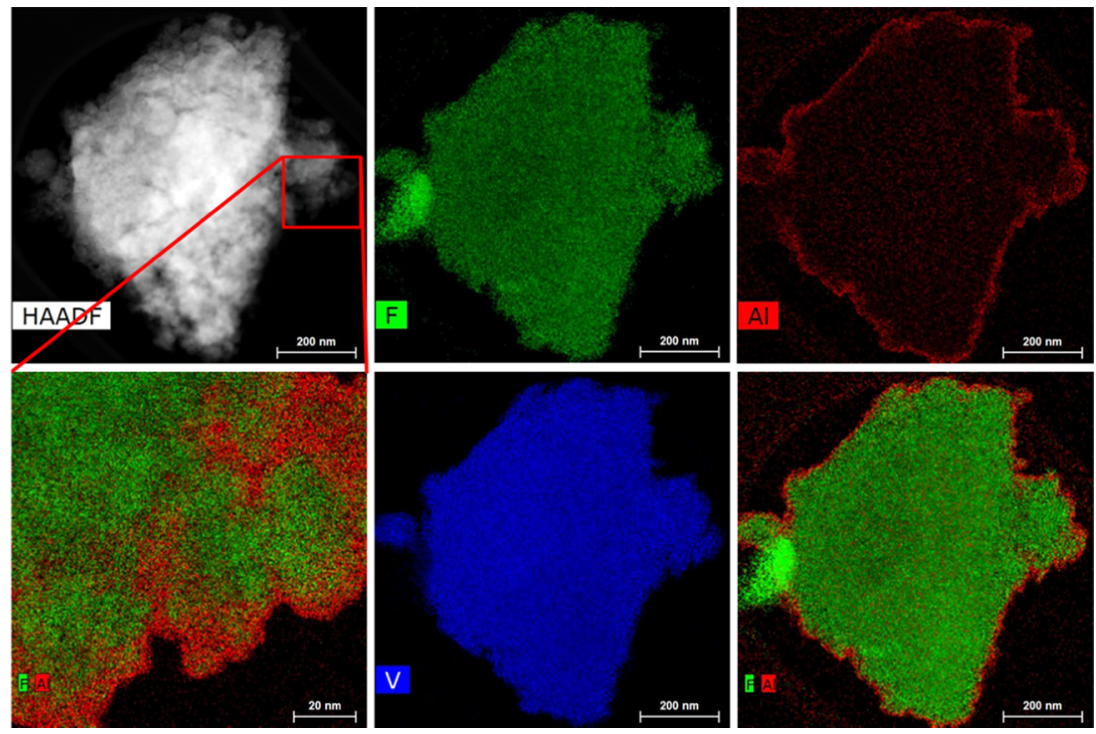

Figure 1. STEM images and EDS elemental chemical maps $(\mathrm{F}, \mathrm{Al}, \mathrm{V})$ of a representative agglomerate particle of $\mathrm{Li}_{2} \mathrm{VO}_{2} \mathrm{~F}$ after surface treatment by $2 \mathrm{~mol} \% \mathrm{AlF}_{3}$.
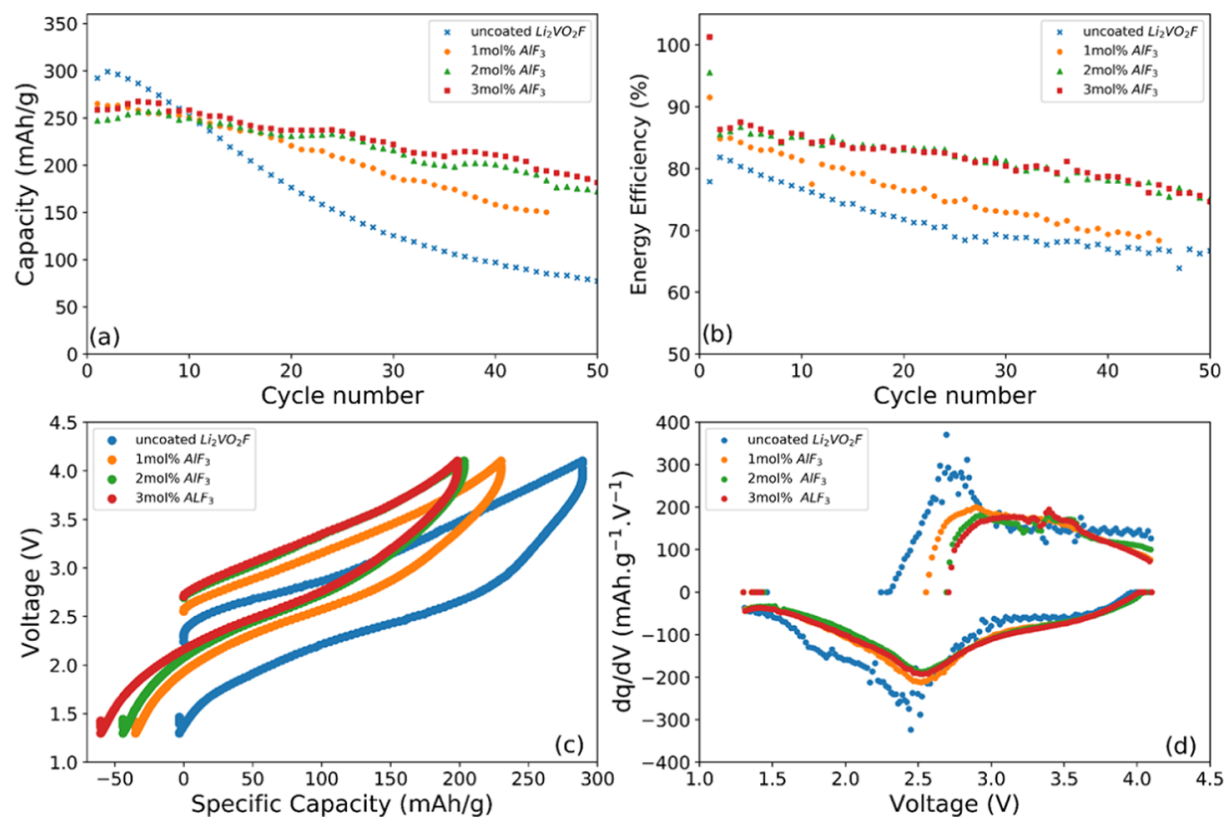

Figure 2. (a) Discharge capacities up to 50 cycles, (b) energy efficiency, (c) first-cycle load curves, and (d) derivative (dQ/dV) plots for untreated and treated $\mathrm{Li}_{2} \mathrm{VO}_{2} \mathrm{~F}$ electrodes during electrochemical cycling.

made was equal to $\left(284.8-\mathrm{BE}\left[\mathrm{C} 1 \mathrm{~s}(\mathrm{C}-\mathrm{C})_{h \nu(\mathrm{C} 1 \mathrm{~s})}\right]\right)+(\mathrm{BE}[\mathrm{Au} 4 \mathrm{f}(7 /$ $\left.\left.2)_{h \nu(\mathrm{Cls})}\right]-\mathrm{BE}\left[\mathrm{Au} 4 \mathrm{f}(7 / 2)_{h \nu(\text { element })}\right]\right)$. In most cases, a peak for the carbon black conductive additive $(\mathrm{C}=\mathrm{C})$ can be fitted close to 284 $\mathrm{eV}$, as for previous studies of such materials, ${ }^{37-39}$ providing further verification of the energy calibration. In the peak model fitting, the peaks corresponding to the PVDF binder were fixed with a splitting of $4.46 \mathrm{eV}$ from each other, according to Beamson and Briggs. ${ }^{40}$

Oxygen ( $\mathrm{O} 1 \mathrm{~s})$ and vanadium $(\mathrm{V} 2 \mathrm{p})$ spectra were measured within the same region. Binding energy positions for the $V 2 p_{3 / 2}$ peaks in the deconvolution were set $-14.7,-14.2$, and $-12.8 \mathrm{eV}$ relative to the metal oxide peak $(\sim 530-531 \mathrm{eV})$ for $\mathrm{V}(\mathrm{III}), \mathrm{V}(\mathrm{IV})$, and $\mathrm{V}(\mathrm{V})$, respectively, as described by Biesinger et al. ${ }^{41}$ This was performed to determine the approximate oxidation states of vanadium in the samples. The $\mathrm{V} 2 \mathrm{p}_{1 / 2}$ peaks were additionally fitted according to a spin-orbit splitting of $7.4 \mathrm{eV} .^{41}$

\section{RESULTS}

3.1. Microstructural and Electrochemical Characterization. The structure of the $\mathrm{AlF}_{3}$-modified and unmodified $\mathrm{Li}_{2} \mathrm{VO}_{2} \mathrm{~F}$ was checked by $\mathrm{X}$-ray diffraction (XRD, see the Supporting Information, Figure $\mathrm{S} 1$ ). The patterns indicate, through identical peak positions and intensities, that the initial rocksalt structure has been retained with no reflections from $\mathrm{AlF}_{3}$ or other $\mathrm{Al}$ compounds evident, because of the low thickness of the surface modification. We observe a slight decrease of the cell parameter from 4.117 to $4.097 \AA$ that may be due to a partial delithiation of the material during the modification process.

To confirm the success of the treatment, the presence of $\mathrm{Al}$ was checked by STEM-EDS (Figure 1). The surface-modified material exhibits the same morphology as the pristine material, 


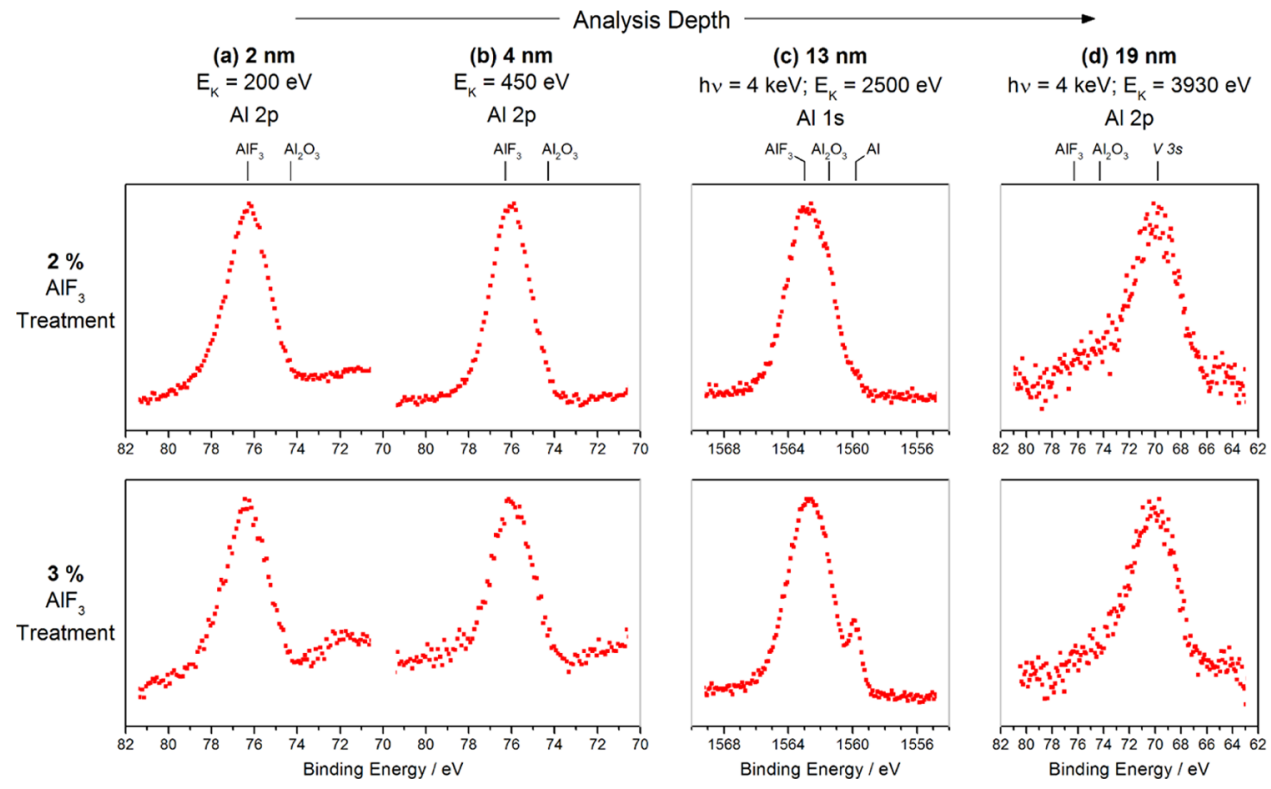

Figure 3. $\mathrm{Al} 2 \mathrm{p} / 1 \mathrm{~s}$ spectra of the uncycled electrodes with both 2 and $3 \% \mathrm{AlF}_{3}$-treated $\mathrm{Li}_{2} \mathrm{VO}_{2} \mathrm{~F}$ active materials. The normalized spectra for four different excitation energies corresponding to different electron kinetic energies and hence probing depths are presented in order from the smallest to greatest depth.

a micrometric agglomerate of smaller primary particles. On the surface of the agglomerate, an Al-rich layer is clearly observable confirming the successful treatment process. In the enlargement (bottom-left), it is possible to see that the 5-10 nm layer is conformal to the particles at the surface of the agglomerate. However, due to the peculiar morphology, it was not possible to determine to what extent the primary particles were treated too. Similarly, it cannot be stated whether the Al-rich layer is a discrete new phase on the active material particles or a modification of the existing surface since both contain fluorine and no definitive interface is observed. Therefore, herein, it is referred to as a particle surface modification or treatment.

The effect of the surface treatment is clear from the galvanostatic cycling tests, as presented in Figure 2a. The unmodified material has an initial discharge capacity of approximately $300 \mathrm{~mA} \mathrm{~h} \mathrm{~g}{ }^{-1}$, which quickly fades as already observed in previous studies. ${ }^{6,14,17}$ On the contrary, the 1-, 2-, and 3\%-treated materials all present a smaller initial capacity of approximately $250 \mathrm{~mA} \mathrm{~h} \mathrm{~g}{ }^{-1}$ but with much higher stability during cycling, outperforming the untreated material after 10 cycles. A significant improvement is observed between the 1and $2 \%$-treated, while the increase from 2 to $3 \%$ brings little further benefit within 50 cycles. Furthermore, the improvement of the energy efficiency of the material when modified is evident in Figure $2 b$.

The lower initial capacity, as well as the increased opencircuit voltage $(\mathrm{OCV})$, supports the hypothesis of a partial delithiation occurring during the treatment process. This delithiation is, however, partly reversible as the first discharge capacities of the treated material are greater than the first charge ones. However, the lower capacities may also indicate that the surface treatments are preventing extensive side reactions such as electrolyte decomposition at the particle surface. In the pristine material, extra capacity can indeed arise from the decomposition reaction of the electrolyte on the active material surface. This reaction consumes electrons and is prevented in the case of $\mathrm{AlF}_{3}$-treated materials as the modified surface limits the contact of the electrolyte with the active material and also prevents the electron transfer due to its insulating nature. The improved energy efficiency mainly arises from a phenomenon observed during the discharge process. As observed in the derivative curves (Figure $2 \mathrm{~d}$ ), the main electrochemical process on discharge is shifted from $2.45 \mathrm{~V}$ for the pristine material to $2.52 \mathrm{~V}$ for the treated material, showing that the treatment process was efficient in reducing the hysteresis of this electrochemical process. Furthermore, an increased contribution of the broad discharge process at $\sim 3.2$ $\mathrm{V}$ demonstrates greater reversibility of the high potential processes. These results indicate that this surface treatment is not acting as a pure barrier against the electrolyte reaction, as this would result in a pure resistive behavior.

3.2. PES Characterization of the Surface Modification. Despite the low thickness of the surface modification preventing its detection by XRD, it can be characterized by analysis of the aluminum PES spectra $(\mathrm{Al} 2 \mathrm{p}$ and $\mathrm{Al} \mathrm{1s})$ at four different probing depths, as presented in Figure 3 . At the smallest probing depths of $2 \mathrm{~nm}$ (a) and $4 \mathrm{~nm}$ (b), the spectra appear very similar with regard to the binding energy $(\sim 76 \mathrm{eV})$ and peak shape. This is a typical binding energy in previous reports ${ }^{42-44}$ of $\mathrm{AlF}_{3}$ and is higher than for aluminum metal or oxides, ${ }^{45,46}$ consistent with the high electronegativity of the coordinating fluorine atoms. However, for the same Al $2 p$ spectrum at the greatest probing depth of $19 \mathrm{~nm}(\mathrm{~d})$, the main peak is at binding energies typically associated with the $\mathrm{V} \mathrm{3s}$ transition. ${ }^{47,48}$ There are signs of some intensity, especially in the $2 \%$-treated sample, at approximately $74-76 \mathrm{eV}$ where we would expect signals for $\mathrm{AlF}_{3}$ and $\mathrm{Al}_{2} \mathrm{O}_{3}$. However, this is a clear indication of how thin the modification is, since at a probing depth of $19 \mathrm{~nm}$, the majority of the signal came from the bulk vanadium-containing active material. At the slightly smaller depth of $13 \mathrm{~nm}$ (c), the Al 1s spectra showed a main peak $(1562.5 \mathrm{eV})$, likely corresponding to $\mathrm{AlF}_{3}{ }^{49}$ The main peak has a shoulder on the lower binding energy side, most clearly observed for the $2 \%$ treatment, likely indicating the presence of an aluminum oxide species. ${ }^{50}$ This could result from mixing between the $\mathrm{AlF}_{3}$ and the active material particles, 


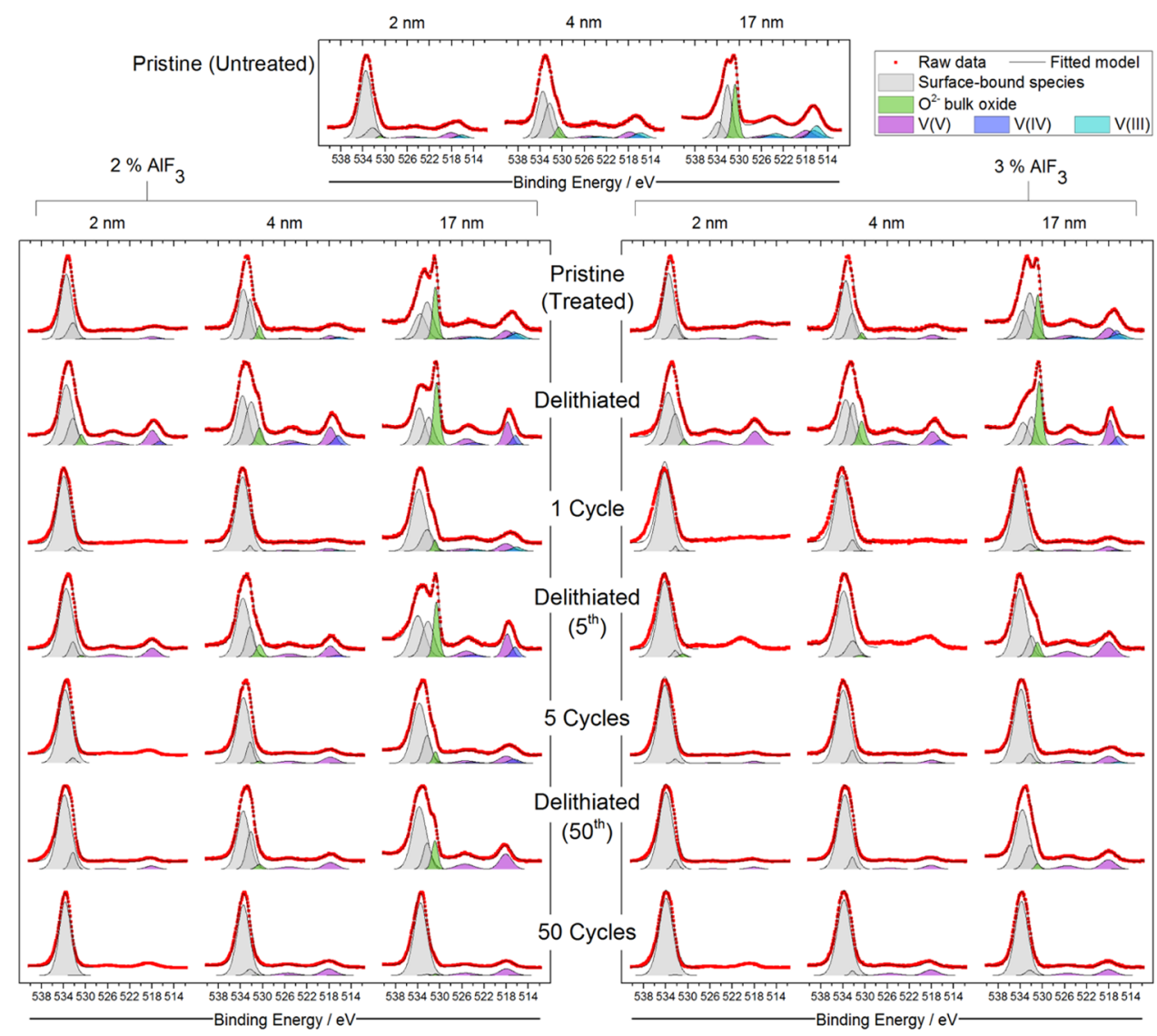

Figure 4. $\mathrm{O} 1 \mathrm{~s}$ and $\mathrm{V} 2 \mathrm{p}$ photoelectron spectra measured in the same region for 2 and $3 \% \mathrm{AlF}_{3}$-treated $\mathrm{Li}_{2} \mathrm{VO}_{2} \mathrm{~F}$ electrodes cycled up to 50 cycles. Peaks for the metal oxide and surface-bound species are fitted in the $\mathrm{O} 1 \mathrm{~s}$ region, while three peaks according to references for $\mathrm{V}^{3+}, \mathrm{V}^{4+}$, and $\mathrm{V}^{5+}$ are fitted in the V 2p region. ${ }^{41}$ Some V signals showed uncharacteristic peak shapes or were too small to be fitted.

as was observed in STEM-EDS measurements, to form $\mathrm{Al}-\mathrm{O}$ environments. A smaller peak $(1560 \mathrm{eV})$ for the $3 \%$ treatment can be assigned to an aluminum metal, which for the $2 \%$ treatment can be observed as a small shoulder to the main peak. $^{51}$ This likely corresponds to some exposed aluminum metal from the current collector, perhaps due to incomplete coverage by the slurry or some pinholes forming during the electrode-drying process. Nevertheless, a comparison of surface and bulk measurements confirms the successful particle surface modification, as expected.

The vanadium signal from the active material is observed in $\mathrm{O} 1 \mathrm{~s}-\mathrm{V} 2 \mathrm{p}$ spectra already at the lowest probing depth, as shown in Figure 4. Due to such contributions from the fluorine-containing active material even at the lowest kinetic energy, it is not possible to perform an accurate quantitative analysis of the surface by the PES measurements. That the vanadium signal is observed at the lowest kinetic energy indicates that the treatment results either in a nonhomogeneous coverage of the particles by a coating or that the existing particle surfaces have been modified. The latter is consistent with the STEM-EDS imaging/mapping and Al XPS regions.

For the $\mathrm{O} 1 \mathrm{~s}-\mathrm{V} 2 \mathrm{p}$ region, a metal oxide-type peak ( $\sim 530-$ $531 \mathrm{eV}$, green) is fitted, assigned to the oxygen in the $\mathrm{Li}_{2} \mathrm{VO}_{2} \mathrm{~F}$ active material. This is a typical binding energy for a vanadium oxide species. ${ }^{41}$ If any $\mathrm{Al}_{2} \mathrm{O}_{3}$ is present as a result of the treatment, the oxide peak would have a very similar binding energy to the oxide of the active material. ${ }^{52}$ However, from the aluminum spectra, we expect this to be a very small contribution. Alongside, at higher binding energies, two other species $(\sim 532 \mathrm{eV}, \sim 533.5-534 \mathrm{eV}$, gray) are included in the model to represent oxygen in typical surface-bound species, such as carbonates or hydroxides. Such species are present in both pristine and treated electrodes, supporting there is not a full coverage of the particles or that a surface modification has taken place. At lower binding energy, peaks $(\sim 516$ and $\sim 524 \mathrm{eV})$ for $\mathrm{V} 2 \mathrm{p}_{3 / 2}$ and $\mathrm{V} 2 \mathrm{p}_{1 / 2}$ are observed, again associated with the active material. In general, the metal oxide peak in the bulk measurements is more intense relative to the surface species peaks for the $2 \%$ electrodes than the $3 \%$, particularly after 1 cycle. It can also be observed that the relative intensity of the vanadium signal is, in most cases, slightly larger in the $2 \%$ than in the $3 \%$ sample. This is likely because the thicker $3 \%$ layer prevents electrons to escape from the $\mathrm{Li}_{2} \mathrm{VO}_{2} \mathrm{~F}$ beneath.

Three peaks were used in the fitting of vanadium; each spin-orbit split by $7.4 \mathrm{eV}$, corresponding to vanadium oxidation states of $\mathrm{V}(\mathrm{III}), \mathrm{V}(\mathrm{IV})$, and $\mathrm{V}(\mathrm{V})$. Binding energies, relative to the metal oxide peak, were used for the fitting of these peaks according to the work of Biesinger et al. ${ }^{41}$ This allows for the separation of contributions from each oxidation state, since in most cases, a mixture of states is observed rather than one fixed state or an "average" state. The untreated pristine electrode exhibited such a mixture of oxidation states with the main contribution from V(III), as evidenced in the bulk measurement $(4 \mathrm{keV})$ and observed previously. ${ }^{14}$ The surface, however, had significant $\mathrm{V}(\mathrm{V})$ and $\mathrm{V}(\mathrm{IV})$ components, demonstrating the susceptibility of the material to oxidation, perhaps during synthesis or electrode processing. On treatment 


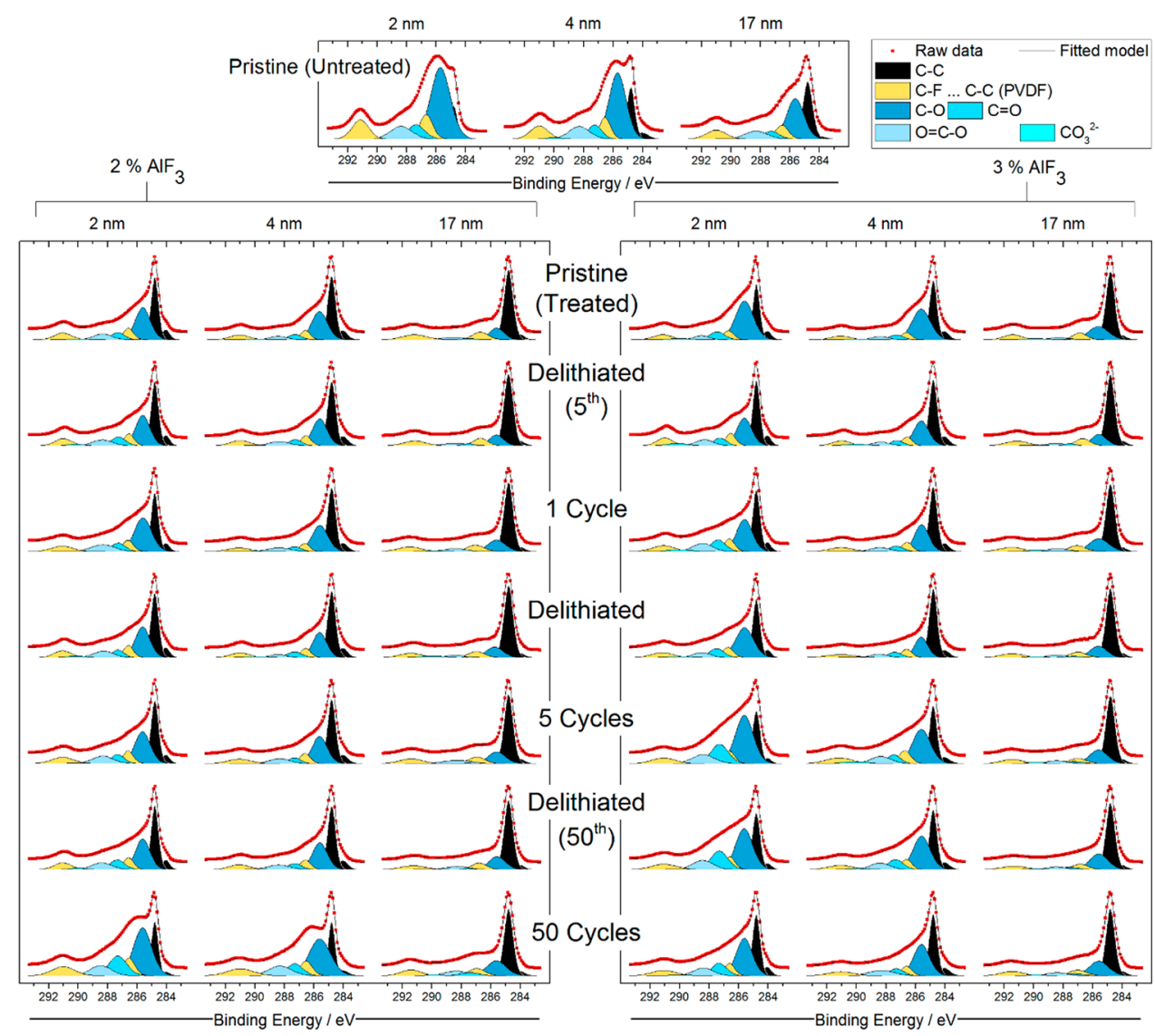

Figure 5. $\mathrm{C} 1 \mathrm{~s}$ photoelectron spectra measured at three different probing depths for 2 and $3 \% \mathrm{AlF}_{3}$-treated $\mathrm{Li}_{2} \mathrm{VO}_{2} \mathrm{~F}$ electrodes cycled up to 50 cycles.

with both 2 and $3 \% \mathrm{AlF}_{3}$, and before assembly of a cell, the vanadium oxidation state shifted to higher values, with a higher proportion of $\mathrm{V}(\mathrm{V})$ in the bulk measurement and a smaller signal from vanadium in surface measurements caused by the surface modification partially blocking the escape of electrons from the $\mathrm{Li}_{2} \mathrm{VO}_{2} \mathrm{~F}$ material. The apparent higher oxidation state of $\mathrm{V}$ in the bulk may indicate that we did not probe the same depth as for the untreated electrode. However, the metal oxide peak was of similar relative intensity to surface species peaks for the bulk measurement, suggesting a similar probing depth. It could therefore be that the active material experienced partial oxidation as a result of exposure to a small amount of water during the $\mathrm{AlF}_{3}$ treatment process.

On delithiation (charge) for both 2- and 3\%-treated electrodes, there is an oxidation of the vanadium; the V(III) peak decreases, while the $\mathrm{V}(\mathrm{V})$ peak increases in relative intensity. This is consistent with the redox activity expected for $\mathrm{Li}_{2} \mathrm{VO}_{2} \mathrm{~F}$, where $\mathrm{V}(\mathrm{III})$ can be oxidized to $\mathrm{V}(\mathrm{V})$ on charge, which is then reduced to $\mathrm{V}$ (III) again on lithiation (discharge). In practice, this does not occur to the maximum extent as determined by its theoretical capacity or with $100 \%$ efficiency, as observed from the electrochemical results and as previously reported. ${ }^{6,14}$ This oxidation-reduction cycling continues on subsequent cycles up to 50 cycles, where there is little sign of any V(III) within the probed depths and the vanadium appeared to retain the $\mathrm{V}(\mathrm{V})$ state. This is similar to that observed for the untreated material in our previous study. ${ }^{14}$ Although the material became redox-inactive in the nearsurface region over the first 50 cycles, it was observed from the electrochemical testing that the treated electrodes still maintain a high capacity at 50 cycles. This indicates that not the whole electrode was oxidized to $\mathrm{V}(\mathrm{V})$ and there was redox-active material in the bulk, which continues to function.

On lithiated electrodes, the signals for surface-bound species (gray) are observed to increase significantly, relative to the metal oxide and vanadium peaks. This is likely a result of the low discharge voltage limit $\left(1.3 \mathrm{~V}\right.$ vs $\left.\mathrm{Li}^{+} / \mathrm{Li}\right)$, where it is possible for electrolyte decomposition to occur at the electrode surface. A similar observation was made for untreated cycled $\mathrm{Li}_{2} \mathrm{VO}_{2} \mathrm{~F}$ electrodes, previously, but with greater intensity from the lower binding energy component. ${ }^{14}$ This suggests a difference in the surface layer formation at low voltages between the untreated and treated electrodes. It is also possible for processes, including oxygen redox, to occur and subsequently react with the electrolyte, forming $\mathrm{PO}_{x} \mathrm{~F}_{y}$ and vanadium-containing compounds at the surface. A fullcoverage $\mathrm{AlF}_{3}$ coating would be expected to act as a passivation layer, preventing extensive continuous electrolyte decomposition at the active material surfaces. However, it appears that the surface modifications do not entirely inhibit electrolyte decomposition but help to limit the reactions between the active material and electrolyte.

Indeed, analyzing the $\mathrm{C}$ 1s spectra as presented in Figure 5, we can determine that there are very few spectral changes upon cycling. C $1 \mathrm{~s}$ spectra are fitted with peaks (black) corresponding to carbon-carbon bonding for the carbon black additive $(\sim 284,284.8 \mathrm{eV})$, two peaks (yellow) for PVDF binder $(\sim 286.5,291 \mathrm{eV})$, and other peaks (blue) corresponding to $\mathrm{C}-\mathrm{O}, \mathrm{C}=\mathrm{O}, \mathrm{O}=\mathrm{C}-\mathrm{O}$, and $\mathrm{CO}_{3}{ }^{2-}(\sim 285.7,287.3$, 288.3, $290 \mathrm{eV})$. Many such peaks are fitted for the pristine- 


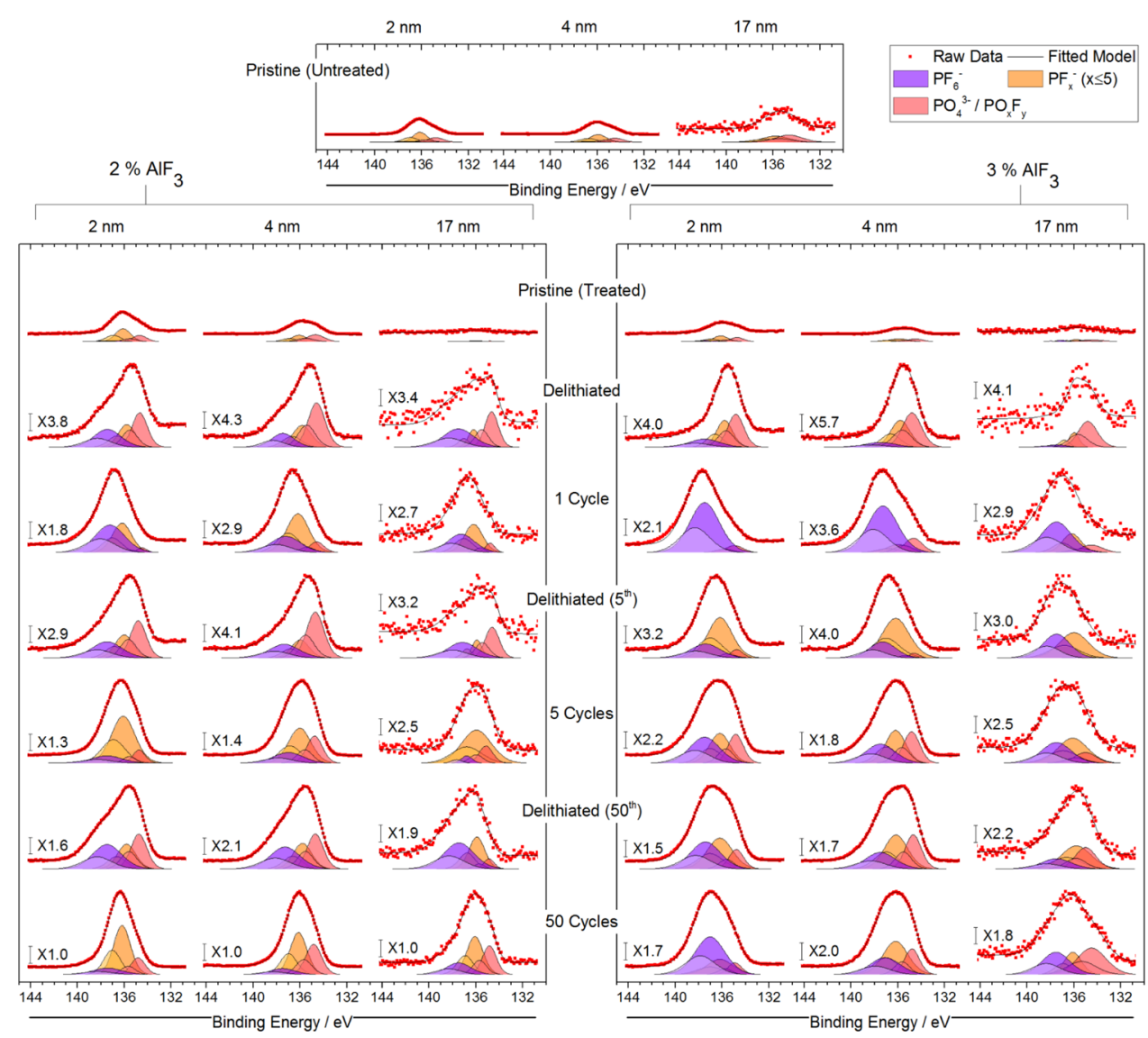

Figure 6. $\mathrm{P} 2 \mathrm{p}$ photoelectron spectra measured at three different probing depths for 2 and $3 \% \mathrm{AlF}_{3}$-treated $\mathrm{Li}_{2} \mathrm{VO}_{2} \mathrm{~F}$ electrodes cycled up to 50 cycles. Each spectrum is normalized, and intensity scaling factors are given referenced against the highest intensity spectrum for each probing depth ( $2 \% \mathrm{AlF}_{3}, 50$ cycles), apart from pristine electrodes where intensities are relatively low.

untreated electrode, which apart from the PVDF peaks indicate the presence of some impurities at the surfaces of the particles. This could result from the ball-milling synthesis employed or from processing inside a glovebox. However, on modification of the particles with $\mathrm{AlF}_{3}$, it can be determined that such surface impurities are substantially removed, likely dissolved during the solution-based treatment process or removed during the heating process.

For cycled untreated electrodes published previously, peaks for carbon-oxygen species were found to increase in intensity, relative to the carbon black peak, over 50 cycles. $^{14}$ This indicated that extensive electrolyte consumption occurs to form an organic-rich interphase layer, while the electrolyte reacts with $\mathrm{Li}_{2} \mathrm{VO}_{2} \mathrm{~F}$, causing degradation of the active material and severe capacity fading. That we observe very little intensity increase of carbon-oxygen species in the C 1s spectra in this study indicates that such processes are limited for the modified materials. Even for the lowest probing depth $(2 \mathrm{~nm})$ measurement after 50 cycles, the carbon black signal is still the most intense of all peaks, indicating minimal layer formation at particle surfaces. It is the $2 \%$-treated electrode after 50 cycles that shows most signs of surface layer formation, with greater intensity for some carbon-oxygen peaks, compared with the 3\%-treated electrode. This may be a first indication of the breakdown of the $\mathrm{AlF}_{3}$ and its failure to passivate the surface structure of the electrode, which is thought to lead to eventual failure. However, at 50 cycles, from the electrochemical results, it appears that both treated electrodes are continuing to perform well.
Despite the carbon spectra displaying very few signs of surface changes or electrolyte decomposition, the same cannot be said for spectra of other elements, particularly phosphorus and fluorine, which originate from the electrolyte salt. Peaks for three different phosphorus environments are fitted to the $\mathrm{P}$ $2 p$ spectra, presented in Figure 6, each exhibiting a spin-orbit splitting of $0.84 \mathrm{eV}^{53}$ Peaks at the lowest binding energy $(\sim 135 \mathrm{eV}$, red) are commonly associated with phosphates or $\mathrm{PO}_{x} \mathrm{~F}_{y}$ species. ${ }^{53,54}$ At $\sim 136.5 \mathrm{eV}$, peaks are fitted (orange) for the decomposition products $\left(\mathrm{PF}_{x}^{-}, x \leq 5\right)$ of the intact electrolyte salt anion $\mathrm{PF}_{6}{ }^{-}$, for which peaks are fitted at $\sim 137.5$ eV. ${ }^{55-57}$

Only a minor amount of phosphorus is detected at the surface region of the pristine electrodes, which is likely a result of contamination from the glovebox environment. Immediately on the first charge, however, we can observe signals for phosphates $/ \mathrm{PO}_{x} \mathrm{~F}_{y}$ compounds in both 2- and 3\%-treated electrodes, suggesting that some salt decomposition already occurs. After 1 cycle, peaks corresponding to $\mathrm{PF}_{6}{ }^{-}$anions are observed for both 2 and 3\%, as well as the $\mathrm{PF}_{6}{ }^{-}$decomposition products, particularly for the $2 \%$ treatment. It is during lithiation that the intensity for phosphorus species is noticed to increase (according to the scaling factors), as was seen for relative intensities of oxygen surface species. This leads us to understand that the oxygen species were likely phosphates or $\mathrm{PO}_{x} \mathrm{~F}_{y}$ compounds. However, the phosphorus spectra also reveal the presence of the intact $\mathrm{PF}_{6}^{-}$salt anion and related decomposition products $\left(\mathrm{PF}_{x}^{-}\right)$at the cycled electrode surfaces. After 5 cycles and 50 cycles, the intensity for these 


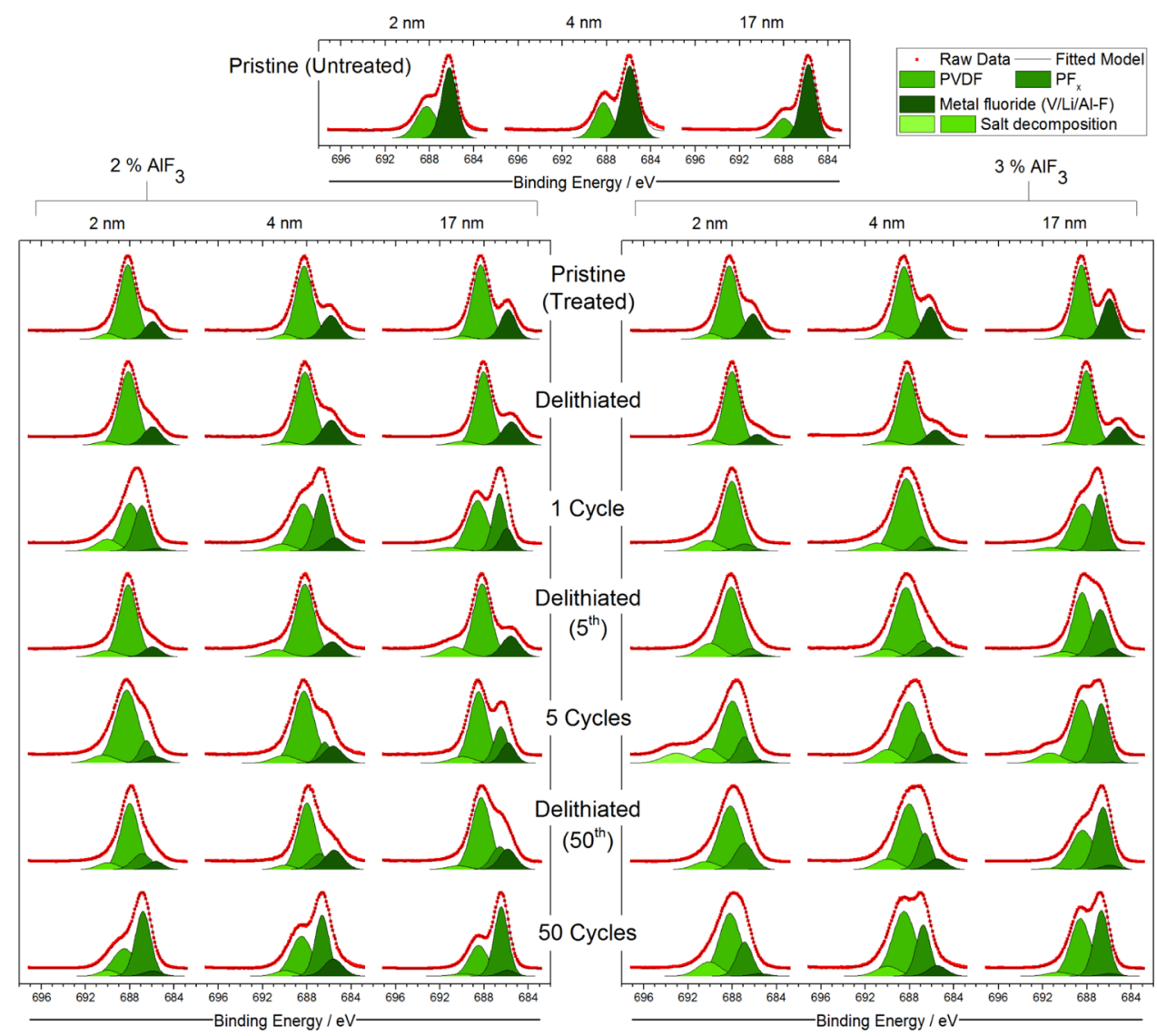

Figure 7. F 1 s photoelectron spectra measured at three different probing depths for 2 and $3 \% \mathrm{AlF}_{3}$-treated $\mathrm{Li}_{2} \mathrm{VO}_{2} \mathrm{~F}$ electrodes cycled up to 50 cycles.

decomposition products becomes especially high for the $2 \%$ treatment. It is significantly lower for the $3 \%$ treatment, with almost equal contributions from $\mathrm{PF}_{6}{ }^{-}$and phosphates $/ \mathrm{PO}_{x} \mathrm{~F}_{y}$ and relatively small changes between states of charge. Despite not observing any formation of organic surface species in the $C$ 1s spectra (typically from the carbonate solvents), the signs of electrolyte salt decomposition are quite clear in the phosphorus spectra. This is similar to previous observations for the cycled untreated material, ${ }^{14}$ where it was inferred that reactions between $\mathrm{Li}_{2} \mathrm{VO}_{2} \mathrm{~F}$ and the $\mathrm{LiPF}_{6}$ electrolyte salt resulted in the degradation of both materials at the surface and progressed gradually into the bulk of the active material. Such degradation is more evident here for the thinner/sparser $2 \%$ $\mathrm{AlF}_{3}$ than for the $3 \% \mathrm{AlF}_{3}$; for the $3 \% \mathrm{AlF}_{3}$, much of the signal from cycled electrodes instead comes from the intact $\mathrm{PF}_{6}{ }^{-}$salt anion. Furthermore, in many bulk spectra, the decomposition products have peaks of equal or greater intensity relative to the $\mathrm{PF}_{6}{ }^{-}$peaks, contrary to those observed in the surface region. This indicates that degradation reactions occur to a larger extent in contact with the active material interface rather than at the surface of the $\mathrm{AlF}_{3}$.

Salt decomposition is additionally evident in F 1s spectra (Figure 7), despite there being many sources of fluorine in the system, including the active material, $\mathrm{AlF}_{3}$ surface layer, and electrolyte. For the pristine-untreated electrodes, we can fit the data with one peak corresponding to the $\mathrm{Li}_{2} \mathrm{VO}_{2} \mathrm{~F}$ active material $(\sim 686 \mathrm{eV})$, typical of a metal fluoride $(\mathrm{V} / \mathrm{Li}-\mathrm{F})$ environment and one for the PVDF binder $\left(\mathrm{CF}_{2}, \sim 688 \mathrm{eV}\right)$. As expected, the active material gives a more intense signal, relative to the PVDF peak, when probing using the highest excitation energy of $4 \mathrm{keV}$, with the PVDF located at the surface of particles. For the $\mathrm{AlF}_{3}$-treated electrodes, we expect the $\mathrm{Al}-\mathrm{F}$ environment to have a similar binding energy to that for the active material, thereby being represented by the same fitted peak. The metal fluoride peak has a higher relative intensity for the $3 \%$-treated material than for the $2 \%$, as would be expected for a thicker $\mathrm{AlF}_{3}$ layer. In pristine-treated electrodes, we observe a much greater intensity for the binder, relative to the metal fluoride, than in the untreated electrodes. This suggests an improved adhesion of the binder to the modified active material particles or a more homogeneous coverage, thereby blocking signals from the metal fluoride. Slightly shifted binding energies for the metal fluoride peak and variations in signal shape depending on the probing depth can be attributed to small differences for the $\mathrm{Al}-\mathrm{F}$ and $\mathrm{Li} / \mathrm{V}-\mathrm{F}$ environments. This is indicative of the presence of $\mathrm{AlF}_{3}$ on the particles.

While few changes are observed on the first delithiation, the shift (up to $0.3 \mathrm{eV}$ ) of the metal fluoride peak to a slightly lower binding energy is likely a consequence of the removal of lithium from the structure, breakup of the protective surface layer and/or particles, or reaction with the electrolyte.

The most significant observations can be made for the samples in the lithiated state, for which an additional peak is fitted between the existing two, corresponding to decomposition products $\left(\mathrm{PF}_{x}{ }^{-}, x \leq 5\right)$ from the $\mathrm{PF}_{6}^{-}$ion. This is particularly apparent for the $2 \%$-treated electrodes after 1 cycle at all probing depths, while for the $3 \%$-treated electrodes, it is only noticeable in the bulk measurement. This strongly suggests that the electrolyte salt reacts with the electrode 


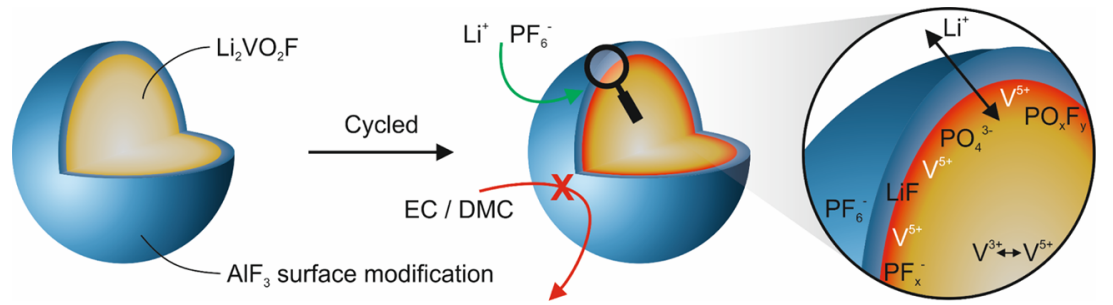

Figure 8. Schematic diagram illustrating the $\mathrm{AlF}_{3}$-treated (blue) $\mathrm{Li}_{2} \mathrm{VO}_{2} \mathrm{~F}$ (yellow) particles. The surface modification acts to suppress the electrolyte solvent decomposition onto the particle surfaces, but some decomposition of the electrolyte salt proceeds. Reaction of the salt at the active material interface results in the formation of various decomposition products, while $\mathrm{Li}$ ions continue to diffuse in and out of the particle and $\mathrm{V}$ undergoes redox processes in the particle bulk.

active material to form such decomposition products. In addition, some intensity between 690 and $693 \mathrm{eV}$ in a few spectra is associated with charging of salt residues deposited on the surface of electrodes; this may indicate a porous nature of the particle surfaces where the salt can be trapped even during washing.

Similar to observations in the oxygen and phosphorus spectra, we can observe here the peak corresponding to $\mathrm{PF}_{6}{ }^{-}$ decomposition products having the highest relative intensity in the lithiation steps. This is true for both the 2- and 3\%-treated electrodes, suggesting that such species are unstable in contact with the active material. However, after 50 cycles, there is a significantly larger intensity for the decomposition product peak in the $2 \%$ than in the $3 \%$, relative to the PVDF and metal fluoride components. This suggests extensive decomposition of the electrolyte salt for the $2 \%$-treated electrodes over 50 cycles. Furthermore, in most cases, the decomposition product has a higher relative intensity in the bulk measurements than at the surface, again indicating that a reaction between the active material and electrolyte salt occurs rather than a typical solid electrolyte interphase (SEI)-type surface layer formation.

The previous study on untreated $\mathrm{Li}_{2} \mathrm{VO}_{2} \mathrm{~F}$ electrodes did not show such dramatic changes in the $\mathrm{F} 1 \mathrm{~s}$ spectra as we see here for the treated electrodes. ${ }^{14}$ In the present study, shifting of the metal fluoride peak to slightly higher binding energies, especially for the lithiated samples, is indicative of the formation of $\mathrm{PF}_{x}^{-}$or $\mathrm{LiF}$, which can be expected as decomposition products from $\mathrm{LiPF}_{6}$. Some intensity from the metal fluoride peak in the middle probing depth measurements (after 50 cycles for 2 and 3\% treatments) can be associated with $\mathrm{LiF}$ formation close to the particle surface. Shifts in the binding energy for $\mathrm{Li} 1 \mathrm{~s}$ signals (Supporting Information, Figure S2) are also indicative of Li-containing species forming at the surface during the lithiation steps.

\section{DISCUSSION}

In previous studies, it was demonstrated that $\mathrm{Li}_{2} \mathrm{VO}_{2} \mathrm{~F}$ cathode materials, despite offering high theoretical capacities, would experience severe capacity fading within the first few cycles. ${ }^{6,8}$ This was attributed to the extensive reaction with the electrolyte and subsequent degradation of the active material and its rapid failure to store charge. ${ }^{14}$ Here, the electrochemical performance of $\mathrm{Li}_{2} \mathrm{VO}_{2} \mathrm{~F}$ has been significantly improved by surface modification with up to $3 \% \mathrm{AlF}_{3}$, allowing cycling with almost $200 \mathrm{~mA} \mathrm{~h} \mathrm{~g}^{-1}$ capacity beyond 50 cycles.

Such treatments/coatings are well known to passivate the active material surface, ideally preventing active material degradation and electrolyte decomposition. Using energytuned photoelectron spectroscopy, we have probed the chemistry of modified active material particles at three depths to understand the role of the $\mathrm{AlF}_{3}$ in protecting the active material. The processes occurring are illustrated schematically in Figure 8. While we do not see much improvement in $\mathrm{V}^{3+} /$ $\mathrm{V}^{5+}$ redox couple reversibility near the particles' surface regions, the main differences from cycled untreated electrodes come when investigating the electrolyte decomposition. In carbon spectra, very little electrolyte solvent decomposition is observed, with few signals for the carbon-oxygen species typically expected when employing carbonate solvents. This is thought to be a direct result of the passivating $\mathrm{AlF}_{3}$, which prevents electron transfer reactions at the particle surfaces, which would otherwise cause the formation of (largely) polymeric surface layers. This is similar to SEI formation at low voltages $\left(\sim 1 \mathrm{~V}\right.$ vs $\left.\mathrm{Li}^{+} / \mathrm{Li}\right)$, which was extensively observed for the untreated electrodes, particularly during lithiation steps. However, for the electrolyte salt, many more signs of decomposition are seen in the spectra for phosphorus and fluorine. Peaks for $\mathrm{PF}_{6}{ }^{-}$salt anion decomposition products such as $\mathrm{PF}_{x}^{-}(x \leq 5), \mathrm{PO}_{x} \mathrm{~F}_{y}$, and phosphates were fitted. Such signals were most intense in the discharge steps where lithium is reinserted into the active material. This proximity of the salt to the particle surface may induce the decomposition of the anion while lithium is intercalated. However, the signals of the salt decomposition products are often more intense from the bulk rather than from the surface. This suggests a direct reaction between the salt and the active material as opposed to the $\mathrm{AlF}_{3}$. Such a reaction may be a result of the instability of the active material and is in line with a degradation mechanism suggested previously. ${ }^{14}$ It could be speculated that the surface modification of such materials may be even more effective in combination with a less reactive salt (e.g., LiTFSI) in the electrolyte. The surface modification provides some protection against active material degradation as is determined from electrochemical cycling tests. However, in the spectroscopy measurements, we notice that this degradation and electrolyte decomposition happen to a greater extent on the $2 \%$ - than on the 3\%-treated electrodes. This supports the hypothesis of the $\mathrm{AlF}_{3}$ treatment forming more of a modified surface than a discrete coating. The $3 \%$ treatment is expected to still exhibit a greater coverage of the active material and protect it from reactions with the electrolyte to a greater extent.

\section{CONCLUSIONS}

Here, we have demonstrated that surface modification of the Li-rich disordered rocksalt cathode material $\mathrm{Li}_{2} \mathrm{VO}_{2} \mathrm{~F}$ with up to $3 \mathrm{~mol} \% \mathrm{AlF}_{3}$ results in much more stable electrochemical cycling. Specific capacities of almost $200 \mathrm{~mA} \mathrm{~h} \mathrm{~g}{ }^{-1}$ could be retained beyond 50 cycles with little capacity fading exhibited 
by the electrodes. In addition, cycling efficiency was markedly improved when employing surface modifications. Our previous studies had proposed a degradation mechanism for the oxyfluoride active material through reaction with the electrolyte and methods for stabilization through doping of the material. We have shown here that the treatment of the material can achieve stabilization, as well as maintain the same theoretical specific capacity. STEM-EDS imaging/mapping confirmed the passivation of the active material by a surface layer of up to $10 \mathrm{~nm}$, rich in aluminum and fluorine. Energytuned photoelectron spectroscopy was used to probe three different depths of the material at stages up to 50 cycles. The measurements demonstrated that the surface modification suppresses the electrolyte solvent decomposition, a common phenomenon that can lead to extensive surface layer buildup and eventual failure of a battery. However, the electrolyte salt $\left(\mathrm{LiPF}_{6}\right)$ decomposition was not completely inhibited. It appears that the salt reacted with the active material, which was still accessible to some extent, resulting in a gradual degradation of the active material. This degradation was, on the other hand, much slower than reported for the untreated material. The process is also more noticeable for the $2 \mathrm{~mol} \%$ treatment than for $3 \%$. We can conclude that $\mathrm{AlF}_{3}$ surface modifications may be employed to stabilize the surface of $\mathrm{Li}_{2} \mathrm{VO}_{2} \mathrm{~F}$ cathode materials, with a positive effect on electrochemical performance. This puts such cathode materials a step closer to becoming promising candidates for use in nextgeneration Li-ion batteries.

\section{ASSOCIATED CONTENT}

\section{S1 Supporting Information}

The Supporting Information is available free of charge at https://pubs.acs.org/doi/10.1021/acsaem.0c00839.

Excitation energies used for SOXPES measurements, calculation of inelastic mean free path of electrons, X-ray diffraction measurements, and $\mathrm{Li} 1 \mathrm{~s}$ photoelectron spectra (PDF)

\section{AUTHOR INFORMATION}

\section{Corresponding Authors}

Andrew J. Naylor - Department of Chemistry-Ångström Laboratory, Uppsala University, 75121 Uppsala, Sweden; 다이.org/0000-0001-5641-7778; Email: andy.naylor@ kemi.uu.se

Daniel Brandell - Department of Chemistry-Ångström Laboratory, Uppsala University, 75121 Uppsala, Sweden; ๑ orcid.org/0000-0002-8019-2801; Email: daniel.brandell@ kemi.uu.se

\section{Authors}

Ida Källquist - Department of Physics and Astronomy, Uppsala University, 75120 Uppsala, Sweden; @ orcid.org/0000-00018333-0088

David Peralta - Université Grenoble-Alpes, CEA-LITEN, 38054 Grenoble Cedex 9, France

Jean-Frederic Martin - Université Grenoble-Alpes, CEALITEN, 38054 Grenoble Cedex 9, France

Adrien Boulineau - Université Grenoble-Alpes, CEA-LITEN, 38054 Grenoble Cedex 9, France

Jean-François Colin - Université Grenoble-Alpes, CEA-LITEN, 38054 Grenoble Cedex 9, France
Christian Baur - Helmholtz Institute Ulm, 89081 Ulm, Germany; 이이이.org/0000-0002-1512-2735

Johann Chable - Helmholtz Institute Ulm, $89081 \mathrm{Ulm}$, Germany; 이이이.org/0000-0003-1134-766X

Maximilian Fichtner - Helmholtz Institute Ulm, $89081 \mathrm{Ulm}$, Germany; Institute of Nanotechnology, Karlsruhe Institute of Technology, 76021 Karlsruhe, Germany

Kristina Edström - Department of Chemistry-Ångstrom Laboratory, Uppsala University, 75121 Uppsala, Sweden; (1) orcid.org/0000-0003-4440-2952

Maria Hahlin - Department of Chemistry-Ångström Laboratory and Department of Physics and Astronomy, Uppsala University, 75121 Uppsala, Sweden; ㅇo이.org/ 0000-0002-5680-1216

Complete contact information is available at:

https://pubs.acs.org/10.1021/acsaem.0c00839

\section{Notes}

The authors declare no competing financial interest.

\section{ACKNOWLEDGMENTS}

This project has received funding from the European Union's Horizon 2020 research and innovation program under grant agreement no. 711792 (LiRichFCC). STandUP for Energy is also acknowledged for financial support. This work was carried out with the support of the Diamond Light Source, instrument I09 (proposal SI20870-1). The research leading to this result has been supported by the project CALIPSOplus under Grant Agreement 730872 from the EU Framework Programme for Research and Innovation HORIZON 2020. This work contributes to the research performed at CELEST (Center for Electrochemical Energy Storage Ulm-Karlsruhe).

\section{REFERENCES}

(1) Rozier, P.; Tarascon, J. M. Review-Li-Rich Layered Oxide Cathodes for Next-Generation Li-Ion Batteries: Chances and Challenges. J. Electrochem. Soc. 2015, 162, A2490-A2499.

(2) Thackeray, M. M.; Kang, S. H.; Johnson, C. S.; Vaughey, J. T.; Benedek, R.; Hackney, S. A. $\mathrm{Li}_{2} \mathrm{MnO}_{3}$-Stabilized $\mathrm{LiMO}_{2}(\mathrm{M}=\mathrm{Mn}$, $\mathrm{Ni}, \mathrm{Co}$ ) Electrodes for Lithium-Ion Batteries. J. Mater. Chem. 2007, $17,3112-3125$.

(3) Naylor, A. J.; Makkos, E.; Maibach, J.; Guerrini, N.; Sobkowiak, A.; Björklund, E.; Lozano, J. G.; Menon, A. S.; Younesi, R.; Roberts, M. R.; Edström, K.; Islam, M. S.; Bruce, P. G. Depth-Dependent Oxygen Redox Activity in Lithium-Rich Layered Oxide Cathodes. J. Mater. Chem. A 2019, 7, 25355-25368.

(4) House, R. A.; Maitra, U.; Jin, L.; Lozano, J. G.; Somerville, J. W.; Rees, N. H.; Naylor, A. J.; Duda, L. C.; Massel, F.; Chadwick, A. V.; Ramos, S.; Pickup, D. M.; McNally, D. E.; Lu, X.; Schmitt, T.; Roberts, M. R.; Bruce, P. G. What Triggers Oxygen Loss in Oxygen Redox Cathode Materials? Chem. Mater. 2019, 31, 3293-3300.

(5) Chen, D.; Kan, W. H.; Chen, G. Understanding Performance Degradation in Cation-Disordered Rock-Salt Oxide Cathodes. Adv. Energy Mater. 2019, 9, No. 1901255.

(6) Chen, R.; Ren, S.; Knapp, M.; Wang, D.; Witter, R.; Fichtner, M.; Hahn, H. Disordered Lithium-Rich Oxyfluoride as a Stable Host for Enhanced $\mathrm{Li}^{+}$Intercalation Storage. Adv. Energy Mater. 2015, 5, No. 1401814.

(7) Clément, R. J.; Lun, Z.; Ceder, G. Cation-Disordered Rocksalt Transition Metal Oxides and Oxyfluorides for High Energy LithiumIon Cathodes. Energy Environ. Sci. 2020, 13, 345-373.

(8) Chen, R.; Ren, S.; Yavuz, M.; Guda, A. A.; Shapovalov, V.; Witter, R.; Fichtner, M.; Hahn, H. $\mathrm{Li}^{+}$Intercalation in Isostructural $\mathrm{Li}_{2} \mathrm{VO}_{3}$ and $\mathrm{Li}_{2} \mathrm{VO}_{2} \mathrm{~F}$ with $\mathrm{O}^{2-}$ and Mixed $\mathrm{O}^{2-} / \mathrm{F}^{-}$Anions. Phys. Chem. Chem. Phys. 2015, 17, 17288-17295. 
(9) Wang, R.; Li, X.; Liu, L.; Lee, J.; Seo, D. H.; Bo, S. H.; Urban, A.; Ceder, G. A Disordered Rock-Salt Li-Excess Cathode Material with High Capacity and Substantial Oxygen Redox Activity: $\mathrm{Li}_{1.25} \mathrm{Nb}_{0.25} \mathrm{Mn}_{0.5} \mathrm{O}_{2}$. Electrochem. Commun. 2015, 60, 70-73.

(10) Lee, J.; Urban, A.; Li, X.; Su, D.; Hautier, G.; Ceder, G. Unlocking the Potential of Cation-Disordered Oxides for Rechargeable Lithium Batteries. Science 2014, 343, 519-522.

(11) Yabuuchi, N.; Nakayama, M.; Takeuchi, M.; Komaba, S.; Hashimoto, Y.; Mukai, T.; Shiiba, H.; Sato, K.; Kobayashi, Y.; Nakao, A.; Yonemura, M.; Yamanaka, K.; Mitsuhara, K.; Ohta, T. Origin of Stabilization and Destabilization in Solid-State Redox Reaction of Oxide Ions for Lithium-Ion Batteries. Nat. Commun. 2016, 7, No. 13814.

(12) Chen, R.; Witte, R.; Heinzmann, R.; Ren, S.; Mangold, S.; Hahn, H.; Hempelmann, R.; Ehrenberg, H.; Indris, S. Identifying the Redox Activity of Cation-Disordered Li-Fe-V-Ti Oxide Cathodes for Li-Ion Batteries. Phys. Chem. Chem. Phys. 2016, 18, 7695-7701.

(13) House, R. A.; Jin, L.; Maitra, U.; Tsuruta, K.; Somerville, J. W.; Förstermann, D. P.; Massel, F.; Duda, L.; Roberts, M. R.; Bruce, P. G. Lithium Manganese Oxyfluoride as a New Cathode Material Exhibiting Oxygen Redox. Energy Environ. Sci. 2018, 11, 926-932.

(14) Källquist, I.; Naylor, A. J.; Baur, C.; Chable, J.; Kullgren, J.; Fichtner, M.; Edström, K.; Brandell, D.; Hahlin, M. Degradation Mechanisms in $\mathrm{Li}_{2} \mathrm{VO}_{2} \mathrm{~F}$ Li-Rich Disordered Rock-Salt Cathodes. Chem. Mater. 2019, 31, 6084-6096.

(15) Seo, D.-H.; Lee, J.; Urban, A.; Malik, R.; Kang, S.; Ceder, G. The Structural and Chemical Origin of the Oxygen Redox Activity in Layered and Cation-Disordered Li-Excess Cathode Materials. Nat. Chem. 2016, 8, 692-697.

(16) Ren, S.; Chen, R.; Maawad, E.; Dolotko, O.; Guda, A. A.; Shapovalov, V.; Wang, D.; Hahn, H.; Fichtner, M. Improved Voltage and Cycling for $\mathrm{Li}^{+}$Intercalation in High-Capacity Disordered Oxyfluoride Cathodes. Adv. Sci. 2015, 2, No. 1500128.

(17) Baur, C.; Källquist, I.; Chable, J.; Chang, J. H.; Johnsen, R. E.; Ruiz-Zepeda, F.; Ateba Mba, J.-M.; Naylor, A. J.; Garcia-Lastra, J. M.; Vegge, T.; Klein, F.; Schür, A. R.; Norby, P.; Edström, K.; Hahlin, M.; Fichtner, M. Improved Cycling Stability in High-Capacity Li-Rich Vanadium Containing Disordered Rock Salt Oxyfluoride Cathodes. J. Mater. Chem. A 2019, 7, 21244-21253.

(18) Cambaz, M. A.; Vinayan, B. P.; Euchner, H.; Pervez, S. A.; Geßwein, H.; Braun, T.; Gross, A.; Fichtner, M. Design and Tuning of the Electrochemical Properties of Vanadium-Based Cation-Disordered Rock-Salt Oxide Positive Electrode Material for Lithium-Ion Batteries. ACS Appl. Mater. Interfaces 2019, 11, 39848-39858.

(19) Shi, S. J.; Tu, J. P.; Tang, Y. Y.; Liu, X. Y.; Zhang, Y. Q.; Wang, X. L.; Gu, C. D. Enhanced Cycling Stability of Li$\left[\mathrm{Li}_{0.2} \mathrm{Mn}_{0.54} \mathrm{Ni}_{0.13} \mathrm{Co}_{0.13}\right] \mathrm{O}_{2}$ by Surface Modification of $\mathrm{MgO}$ with Melting Impregnation Method. Electrochim. Acta 2013, 88, 671-679.

(20) Kim, S. J.; Kim, M. C.; Kwak, D. H.; Kim, D. M.; Lee, G. H.; Choe, H. S.; Park, K. W. Highly Stable $\mathrm{TiO}_{2}$ Coated $\mathrm{Li}_{2} \mathrm{MnO}_{3}$ Cathode Materials for Lithium-Ion Batteries. J. Power Sources 2016, 304, 119-127.

(21) Wu, Y.; Ming, J.; Zhuo, L.; Yu, Y.; Zhao, F. Simultaneous Surface Coating and Chemical Activation of the Li-Rich Solid Solution Lithium Rechargeable Cathode and Its Improved Performance. Electrochim. Acta 2013, 113, 54-62.

(22) Zhang, X.; Belharouak, I.; Li, L.; Lei, Y.; Elam, J. W.; Nie, A.; Chen, X.; Yassar, R. S.; Axelbaum, R. L. Structural and Electrochemical Study of $\mathrm{Al}_{2} \mathrm{O}_{3}$ and $\mathrm{TiO}_{2}$ Coated $\mathrm{Li}_{1.2} \mathrm{Ni}_{0.13} \mathrm{Mn}_{0.54} \mathrm{Co}_{0.13} \mathrm{O}_{2}$ Cathode Material Using ALD. Adv. Energy Mater. 2013, 3, 12991307.

(23) Hall, D. S.; Gauthier, R.; Eldesoky, A.; Murray, V. S.; Dahn, J. R. New Chemical Insights into the Beneficial Role of $\mathrm{Al}_{2} \mathrm{O}_{3}$ Cathode Coatings in Lithium-Ion Cells. ACS Appl. Mater. Interfaces 2019, 11, 14095-14100.

(24) Zheng, J.; Gu, M.; Xiao, J.; Polzin, B. J.; Yan, P.; Chen, X.; Wang, C.; Zhang, J. G. Functioning Mechanism of $\mathrm{AlF}_{3}$ Coating on the Li- and Mn-Rich Cathode Materials. Chem. Mater. 2014, 26, 6320-6327.
(25) Rosina, K. J.; Jiang, M.; Zeng, D.; Salager, E.; Best, A. S.; Grey, C. P. Structure of Aluminum Fluoride Coated $\mathrm{Li}\left[\mathrm{Li}_{1 / 9} \mathrm{Ni}_{1 / 3} \mathrm{Mn}_{5 / 9}\right] \mathrm{O}_{2}$ Cathodes for Secondary Lithium-Ion Batteries. J. Mater. Chem. 2012, 22, 20605-20610.

(26) Amalraj, F.; Talianker, M.; Markovsky, B.; Burlaka, L.; Leifer, N.; Goobes, G.; Erickson, E. M.; Haik, O.; Grinblat, J.; Zinigrad, E.; Aurbach, D.; Lampert, J. K.; Shin, J.-Y.; Schulz-Dobrick, M.; Garsuch, A. Studies of $\mathrm{Li}$ and $\mathrm{Mn}-\mathrm{Rich} \mathrm{Li}_{\mathrm{x}}[\mathrm{MnNiCo}] \mathrm{O}_{2}$ Electrodes: Electrochemical Performance, Structure, and the Effect of the Aluminum Fluoride Coating. J. Electrochem. Soc. 2013, 160, A2220-A2233.

(27) Zheng, F.; Yang, C.; Xiong, X.; Xiong, J.; Hu, R.; Chen, Y.; Liu, M. Nanoscale Surface Modification of Lithium-Rich Layered-Oxide Composite Cathodes for Suppressing Voltage Fade. Angew. Chem., Int. Ed. 2015, 54, 13058-13062.

(28) Erickson, E. M.; Schipper, F.; Penki, T. R.; Shin, J. Y.; Erk, C.; Chesneau, F. F.; Markovsky, B.; Aurbach, D. Review-Recent Advances \& Remaining Challenges for Lithium Ion Battery Cathodes II. Lithium-Rich, $\mathrm{xLi}_{2} \mathrm{MnO}_{3} \cdot(1-\mathrm{x}) \mathrm{LiNi}_{\mathrm{a}} \mathrm{Co}_{\mathrm{b}} \mathrm{Mn}_{\mathrm{c}} \mathrm{O}_{2}$. J. Electrochem. Soc. 2017, 164, A6341-A6348.

(29) Schipper, F.; Erickson, E. M.; Erk, C.; Shin, J. Y.; Chesneau, F. F.; Aurbach, D. Review-Recent Advances and Remaining Challenges for Lithium Ion Battery Cathodes I. Nickel-Rich, $\mathrm{LiNi}_{\mathrm{x}} \mathrm{Co}_{\mathrm{y}} \mathrm{Mn}_{\mathrm{z}} \mathrm{O}_{2}$. J. Electrochem. Soc. 2017, 164, A6220-A6228.

(30) Dogan, F.; Vaughey, J. T.; Iddir, H.; Key, B. Direct Observation of Lattice Aluminum Environments in $\mathrm{Li}$ Ion Cathodes $\mathrm{Li}$ $\mathrm{Ni}_{1-\mathrm{y}-\mathrm{z}} \mathrm{Co}_{\mathrm{y}} \mathrm{Al}_{\mathrm{z}} \mathrm{O}_{2}$ and Al-Doped $\mathrm{LiNi}_{\mathrm{x}} \mathrm{Mn}_{\mathrm{y}} \mathrm{Co}_{\mathrm{z}} \mathrm{O}_{2}$ via ${ }^{27} \mathrm{Al}$ MAS NMR Spectroscopy. ACS Appl. Mater. Interfaces 2016, 8, 16708-16717.

(31) Riley, L. A.; Van Atta, S.; Cavanagh, A. S.; Yan, Y.; George, S. M.; Liu, P.; Dillon, A. C.; Lee, S. H. Electrochemical Effects of ALD Surface Modification on Combustion Synthesized Li$\mathrm{Ni}_{1 / 3} \mathrm{Mn}_{1 / 3} \mathrm{Co}_{1 / 3} \mathrm{O}_{2}$ as a Layered-Cathode Material. J. Power Sources 2011, 196, 3317-3324.

(32) Wang, X.; Wang, X.; Lu, Y. Realizing High Voltage Lithium Cobalt Oxide in Lithium-Ion Batteries. Ind. Eng. Chem. Res. 2019, 58, 10119-10139.

(33) Wang, X.; Huang, Y.; Ji, D.; Omenya, F.; Karki, K.; Sallis, S.; Piper, L. F. J.; Wiaderek, K. M.; Chapman, K. W.; Chernova, N. A.; Whittingham, M. S. Structure Evolution and Thermal Stability of High-Energy-Density Li-Ion Battery Cathode $\mathrm{Li}_{2} \mathrm{VO}_{2} \mathrm{~F}$. J. Electrochem. Soc. 2017, 164, A1552-A1558.

(34) Baur, C.; Chable, J.; Klein, F.; Chakravadhanula, V. S. K.; Fichtner, M. Reversible Delithiation of Disordered Rock Salt $\mathrm{LiVO}_{2}$. ChemElectroChem 2018, 5, 1484-1490.

(35) Lee, T. L.; Duncan, D. A. A Two-Color Beamline for Electron Spectroscopies at Diamond Light Source. Synchrotron Radiat. News 2018, 31, 16-22.

(36) Powell, C. J.; Jablonski, A.. NIST Electron Inelastic-Mean-FreePath Database, version 1.2, SRD 71. National Institute of Standards and Technology: Gaithersburg, MD, 2010.

(37) Philippe, B.; Dedryvère, R.; Gorgoi, M.; Rensmo, H.; Gonbeau, D.; Edström, K. Improved Performances of Nanosilicon Electrodes Using the Salt LiFSI: A Photoelectron Spectroscopy Study. J. Am. Chem. Soc. 2013, 135, 9829-9842.

(38) Parimalam, B. S.; MacIntosh, A. D.; Kadam, R.; Lucht, B. L. Decomposition Reactions of Anode Solid Electrolyte Interphase (SEI) Components with $\mathrm{LiPF}_{6}$. J. Phys. Chem. C 2017, 121, 2273322738.

(39) Lindgren, F.; Xu, C.; Niedzicki, L.; Marcinek, M.; Gustafsson, T.; Björefors, F.; Edström, K.; Younesi, R. SEI Formation and Interfacial Stability of a Si Electrode in a LiTDI-Salt Based Electrolyte with FEC and VC Additives for Li-Ion Batteries. ACS Appl. Mater. Interfaces 2016, 8, 15758-15766.

(40) Beamson, G.; Briggs, D. High Resolution XPS of Organic Polymers: The Scienta ESCA300 Database; Wiley, 1992.

(41) Biesinger, M. C.; Lau, L. W. M.; Gerson, A. R.; Smart, R. S. C. Resolving Surface Chemical States in XPS Analysis of First Row Transition Metals, Oxides and Hydroxides: Sc, Ti, V, Cu and $\mathrm{Zn}$. Appl. Surf. Sci. 2010, 257, 887-898. 
(42) Hess, A.; Kemnitz, E.; Lippitz, A.; Unger, W. E. S.; Menz, D. H. ESCA, XRD, and IR Characterization of Aluminum Oxide, Hydroxyfluoride, and Fluoride Surfaces in Correlation with Their Catalytic Activity in Heterogeneous Halogen Exchange Reactions. J. Catal. 1994, 148, 270-280.

(43) Mcguire, G. E.; Schweitzer, G. K.; Carlson, T. A. Study of Core Electron Binding Energies in Some Group IIIa, Vb, and VIb Compounds. Inorg. Chem. 1973, 12, 2450-2453.

(44) Younan, H.; Xiang, X. Z.; Xiaomin, L. In Characterization Studies of Fluorine-Induced Corrosion Crystal Defects on Microchip Al Bondpads Using X-Ray Photoelectron Spectroscopy, Proceedings of the International Symposium on the Physical and Failure Analysis of Integrated Circuits, IPFA. Institute of Electrical and Electronics Engineers Inc., 2014; pp 90-93.

(45) Strohmeier, B. R. Gamma-Alumina $\left(\gamma-\mathrm{Al}_{2} \mathrm{O}_{3}\right)$ by XPS. Surf. Sci. Spectra 1994, 3, 135-140.

(46) Strohmeier, B. R. Surface Characterization of Aluminum Foil Annealed in the Presence of Ammonium Fluoborate. Appl. Surf. Sci. 1989, 40, 249-263.

(47) Światowska-Mrowiecka, J.; Maurice, V.; Zanna, S.; Klein, L.; Marcus, P. XPS Study of Li Ion Intercalation in $\mathrm{V}_{2} \mathrm{O}_{5}$ Thin Films Prepared by Thermal Oxidation of Vanadium Metal. Electrochim. Acta 2007, 52, 5644-5653.

(48) Zimmermann, R.; Steiner, P.; Claessen, R.; Reinert, F.; Hüfner, S. Electronic Structure Systematics of 3d Transition Metal Oxides. J. Electron Spectrosc. Relat. Phenom. 1998, 96, 179-186.

(49) Kobayashi, G.; Irii, Y.; Matsumoto, F.; Ito, A.; Ohsawa, Y.; Yamamoto, S.; Cui, Y.; Son, J. Y.; Sato, Y. Improving Cycling Performance of Li-Rich Layered Cathode Materials through Combination of $\mathrm{Al}_{2} \mathrm{O}_{3}$-Based Surface Modification and Stepwise Precycling. J. Power Sources 2016, 303, 250-256.

(50) Castle, J. E.; Hazell, L. B.; Whitehead, R. D. X-Ray Photoelectron Spectroscopy Using $\mathrm{Si} \mathrm{K} \alpha$ Radiation. J. Electron Spectrosc. Relat. Phenom. 1976, 9, 247-250.

(51) Yates, K.; West, R. H. Monochromatized Ag L $\alpha$ X-Rays as a Source for Higher Energy XPS. Surf. Interface Anal. 1983, 5, 133-138.

(52) Strohmeier, B. R.; Hercules, D. M. Surface Spectroscopic Characterization of Manganese/Aluminum Oxide Catalysts. J. Phys. Chem. A 1984, 88, 4922-4929.

(53) Moulder, J. F.; Chastain, J. Handbook of X-Ray Photoelectron Spectroscopy: A Reference Book of Standard Spectra for Identification and Interpretation of XPS Data; Physical Electronics DivisionPhysical Electronics Division; Perkin-Elmer Corporation, 1992.

(54) Schulz, N.; Hausbrand, R.; Dimesso, L.; Jaegermann, W. XPSSurface Analysis of SEI Layers on Li-Ion Cathodes: Part I. Investigation of Initial Surface Chemistry. J. Electrochem. Soc. 2018, 165, A819-A832.

(55) Andersson, A. M.; Abraham, D. P.; Haasch, R.; MacLaren, S.; Liu, J.; Amine, K. Surface Characterization of Electrodes from High Power Lithium-Ion Batteries. J. Electrochem. Soc. 2002, 149, A1358A1369.

(56) Ensling, D.; Stjerndahl, M.; Nytén, A.; Gustafsson, T.; Thomas, J. O. A Comparative XPS Surface Study of $\mathrm{Li}_{2} \mathrm{FeSiO}_{4} / \mathrm{C}$ Cycled with LiTFSI- and $\mathrm{LiPF}_{6}$-Based Electrolytes. J. Mater. Chem. 2009, 19, 8288.

(57) Herstedt, M.; Stjerndahl, M.; Nytén, A.; Gustafsson, T.; Rensmo, H.; Siegbahn, H.; Ravet, N.; Armand, M.; Thomas, J. O.; Edström, K. Surface Chemistry of Carbon-Treated $\mathrm{LiFePO}_{4}$ Particles for Li-Ion Battery Cathodes Studied by PES. Electrochem. Solid-State Lett. 2003, 6, A202-A206. 